OPEN ACCESS

Edited by:

Joaquin Bautista-Gallego, Instituto de la Grasa (CSIC), Spain

Reviewed by:

Maria Aponte,

University of Naples Federico II, Italy

Braulio Esteve-Zarzoso,

Rovira i Virgili University, Spain

${ }^{*}$ Correspondence:

Amparo Querol

aquero/@iata.csic.es

Specialty section: This article was submitted to

Food Microbiology,

a section of the journal

Frontiers in Microbiology

Received: 05 December 2016

Accepted: 20 January 2017

Published: 07 February 2017

Citation:

Alonso-del-Real J, Lairón-Peris M, Barrio E and Querol A (2017) Effect of

Temperature on the Prevalence of

Saccharomyces Non cerevisiae Species against a S. cerevisiae Wine

Strain in Wine Fermentation:

Competition, Physiological Fitness,

and Influence in Final Wine

Composition. Front. Microbiol. 8:150.

doi: 10.3389/fmicb.2017.00150

\section{Effect of Temperature on the} Prevalence of Saccharomyces Non cerevisiae Species against a $S$. cerevisiae Wine Strain in Wine Fermentation: Competition, Physiological Fitness, and Influence in Final Wine Composition

\author{
Javier Alonso-del-Real ${ }^{1}$, María Lairón-Peris ${ }^{1,2}$, Eladio Barrio ${ }^{1,2}$ and Amparo Querol ${ }^{1 *}$ \\ ${ }^{1}$ Departamento de Biotecnología de los Alimentos, Grupo de Biología de Sistemas en Levaduras de Interés Biotecnológico, \\ Instituto de Agroquímica y Tecnología de los Alimentos (IATA)-CSIC, Valencia, Spain, ${ }^{2}$ Departament de Genètica, Universitat \\ de València, València, Spain
}

Saccharomyces cerevisiae is the main microorganism responsible for the fermentation of wine. Nevertheless, in the last years wineries are facing new challenges due to current market demands and climate change effects on the wine quality. New yeast starters formed by non-conventional Saccharomyces species (such as S. uvarum or S. kudriavzevii) or their hybrids (S. cerevisiae x S. uvarum and S. cerevisiae $\times$ S. kudriavzevii) can contribute to solve some of these challenges. They exhibit good fermentative capabilities at low temperatures, producing wines with lower alcohol and higher glycerol amounts. However, S. cerevisiae can competitively displace other yeast species from wine fermentations, therefore the use of these new starters requires an analysis of their behavior during competition with $S$. cerevisiae during wine fermentation. In the present study we analyzed the survival capacity of non-cerevisiae strains in competition with S. cerevisiae during fermentation of synthetic wine must at different temperatures. First, we developed a new method, based on QPCR, to quantify the proportion of different Saccharomyces yeasts in mixed cultures. This method was used to assess the effect of competition on the growth fitness. In addition, fermentation kinetics parameters and final wine compositions were also analyzed. We observed that some cryotolerant Saccharomyces yeasts, particularly S. uvarum, seriously compromised S. cerevisiae fitness during competences at lower temperatures, which explains why S. uvarum can replace $S$. cerevisiae during wine fermentations in European regions with oceanic and continental climates. From an enological point of view, mixed co-cultures between S. cerevisiae and S. paradoxus or $S$. eubayanus, deteriorated fermentation parameters and the final product composition compared to single S. cerevisiae inoculation. However, in co-inoculated synthetic must in which $S$. kudriavzevii or $S$. uvarum coexisted with 
S. cerevisiae, there were fermentation performance improvements and the final wines contained less ethanol and higher amounts of glycerol. Finally, it is interesting to note that in co-inoculated fermentations, wine strains of $S$. cerevisiae and S. uvarum performed better than non-wine strains of the same species.

Keywords: Saccharomyces species, competition, wine fermentation, temperature, fitness, wine composition

\section{INTRODUCTION}

Wine is the product of complex interactions among yeast, bacteria and other fungi that begin in vineyards and continue with the fermentation process. Different yeast species are predominant on the surface of grape skins and in the winery environment (Sabate et al., 2002; Albergaria and Arneborg, 2016), and S. cerevisiae is recognized as being the main microorganism responsible for this process (Pretorius, 2000). However, other Saccharomyces species (Saccharomyces noncerevisiae yeasts, SNC) may play an important role in wine fermentation under certain conditions. In this way $S$. uvarum is less frequent than $S$. cerevisiae in wines, but appears to be predominant in European wine regions with an oceanic climate where wine fermentations are performed at lower temperatures; e.g., the Basque Country, Spain (Rementeria, 2003), Alsace, France (Demuyter et al., 2004), Val de Loire, Sauternes, and Jurançon in France (Naumov et al., 2000), Valpolicella, Italy (Torriani et al., 1999), Tokaj in Hungary and Slovakia (Sipiczki et al., 2001; Naumov et al., 2002; Antunovics et al., 2005), and Yalta, the Ukraine (Naumov and Nikonenko, 1987). S. paradoxus is a natural species worldwide distributed with a fortuitous presence in vineyards and fermentation processes (Valero et al., 2007). However, some strains of this species have been described as predominant in Croatian vineyards (Redžepović et al., 2002), and exhibit interesting enological properties.

The fermentations conducted by natural interspecific Saccharomyces hybrids, such as S.cerevisiae $\times$ S.kudriavzevii and S.cerevisiae $\times$ S.uvarum, have also been described in European wine regions with oceanic and continental climates (northern Spain, Alsace, Germany, Switzerland, Austria, Croatia, Hungary, and Moldavia), close to the northern limit of grapevine distribution (Masneuf et al., 1998; González et al., 2006; Erny et al., 2012; Peris et al., 2012).

Despite these exceptions, presence of SNC in the final stages of the fermentation process is quite rare. This is because $S$. cerevisiae can competitively displace other yeast species from wine fermentations, both SNC (Arroyo-López et al., 2011; Williams et al., 2015) and non Saccharomyces yeasts (Holm Hansen et al., 2001; Pérez-Nevado et al., 2006). Different mechanisms have been proposed to explain the higher competing capability of $S$. cerevisiae compared to non Saccharomyces yeasts which, in most cases, are not mutually exclusive, but complementary.

The vigorous fermentative capacity of $S$. cerevisiae yeasts in both the presence (Crabtree effect) and absence of oxygen, has been recognized as the main strategy to outcompete other microbial species present in must. S. cerevisiae consumes sugar resources faster, and the ethanol and $\mathrm{CO}_{2}$ produced during fermentation can be harmful or less tolerated by their competitors. Once competitors are overcome, S. cerevisiae can then use accumulated ethanol as a substrate for aerobic respiration. This ecological strategy is called (ethanol) makeaccumulate-consume (Thomson et al., 2005; Piškur et al., 2006), and provides a selective advantage to $S$. cerevisiae to outcompete other microorganisms. Different non Saccharomyces yeast, as well as bacteria, have also been proven to be very sensitive to the killer peptides or toxic compounds produced by S. cerevisiae (PérezNevado et al., 2006; Albergaria et al., 2010; Branco et al., 2014; Wang et al., 2015, 2016), which may play a key role during competition. Finally, the higher S. cerevisiae cell density has also been postulated as being an important factor that contribute to the exclusion of non Saccharomyces yeasts (Holm Hansen et al., 2001; Nissen et al., 2003, 2004; Nissen and Arneborg, 2003; Arneborg et al., 2005).

Other Saccharomyces species share very similar physiological properties with $S$. cerevisiae and, hence, similar ecological strategies. However, wine S. cerevisiae yeasts show better adaptation to survive under the stressful environmental conditions occurring during alcohol fermentation; e.g., high concentrations of sugar or ethanol, low $\mathrm{pH}$ and nutritional depletion, which provides them with a competitive advantage (Albergaria and Arneborg, 2016).

Another important advantage of S. cerevisiae on SNC species is its efficient growth at a wide range of temperatures, especially at higher temperatures $\left(32^{\circ} \mathrm{C}\right)$. This has also been considered an important trait that explains its dominance during wine fermentation (Salvadó et al., 2011a). Goddard (2008) also observed that S. cerevisiae is even able to significantly increase the environmental temperature during vigorous fermentation. Arroyo-López et al. (2011) also demonstrated that S. cerevisiae was able to outcompete $S$. kudriavzevii even at temperatures that are more suitable to the latter (Salvadó et al., 2011b). However, S. paradoxus has been shown to be present during grape fermentation processes when competing with $S$. cerevisiae at both 22 and $30^{\circ} \mathrm{C}$ (Williams et al., 2015). Therefore, very little is known about the behavior of other SNC in competition with S. cerevisiae in winemaking environments at low temperatures.

In the Twenty-First century, the wine industry must respond to the challenges posed by both new consumers' demands and changes in grape composition and properties due to climate change. Consumers demand products with lower alcohol content and fruitier aromas, which lead winemakers to lower fermentation temperatures, as far as $10-12^{\circ} \mathrm{C}$, to preserve aroma compounds in wines. Climate change influences grape must characteristics (acidity, content in sugars or tannins, etc.), which has an impact on final product quality. Also due to climatic change there is a gap between the maturity according to sugar content and the maturity of the phenolic compounds of the grape. 
Therefore, sugar concentration in musts reaches higher levels, which leads to wines with higher ethanol content.

These facts strongly challenge the quality and acceptance of the final product which leads to the necessity of improvements in oenological practices, among which the development of new yeast starters adapted to the new imposed conditions are of chief importance. Previous studies have shown that unconventional SNC yeast species, such as S. kudriavzevii and $S$. uvarum, could be good candidates to achieve those goals. This is because they exhibit good fermentative capabilities at low temperatures (Salvadó et al., 2011b), produce wines with lower alcohol and higher glycerol amounts (Arroyo-López et al., 2010; Oliveira et al., 2014; Pérez-Torrado et al., 2016), and contribute with good aromatic profiles (Gonzalez et al., 2007; Lopandic et al., 2007; Díaz-Montaño et al., 2008; Gamero et al., 2011, 2013, 2014; Stribny et al., 2015). As well as S. uvarum and S. kudriavzevii, we also included S. paradoxus, the closest species to S. cerevisiae among those of the Saccharomyces genera, which has been already tested for its fermentative capacity as we mentioned above; and $S$. eubayanus, the cryotolerant and recently discovered parental of lager yeast, found in natural fermented beverages from indigenous South American communities (Rodríguez et al., 2014), which makes it a good candidate for screening new properties that might increase the diversity of current commercial wines. Yet despite their potential, these species may have difficulties in competing at the industry level with $S$. cerevisiae, which in most of the cases exhibits better ethanol resistance and the ability to ferment at higher temperatures.

In the present study, we analyzed the survival capacity of SNC in competing with $S$. cerevisiae during fermentation at different temperatures to identify those traits that influence their competitive capabilities and to evaluate their industrial potential. Whereas, genetic markers are the standard to differentiate Saccharomyces strains in a complex culture, a quantitative PCR (QPCR)-based approach was designed to avoid them and their possible effect on gene expression or relative fitness. This approach consists on a relative quantification of the proportion of cells based on the QPCR amplification of a gene with speciesspecific primers using total DNA isolated from a mix of two strains.

\section{MATERIALS AND METHODS}

\section{Yeast Strains}

Seven different Saccharomyces strains were used in our experiments. We chose a commercial strain, T73 (Lalvin T73 from Lallemand Montreal, Canada), as our wine S. cerevisiae representative. We also included YPS128, a S. cerevisiae strain isolated from Pennsylvania woodlands; S. paradoxus strain 54, isolated from Croatian vineyards; two S. uvarum strains, BMV58, selected in our laboratory and commercialized for winemaking (VELLUTOBMV58 $8^{\mathrm{TM}}$ from Lallemand), and CECT12600, isolated from a non-fermented beverage (mistela) in Alicante, Spain; S. eubayanus strain NPCC1292 is a natural isolate from North Patagonian Mudai, traditional fermentation made with
Araucaria araucana seeds; and S. kudriavzevii strain CR85, a natural isolate from oak tree bark in Agudo, Ciudad Real, Spain.

\section{Synthetic Must Fermentations}

For all our experiments, fermentations were performed in $3 \mathrm{x}$ or $6 \mathrm{x}$ replicates in $250 \mathrm{~mL}$ flasks that contained $200 \mathrm{~mL}$ of synthetic must (SM), which is frequently used in microvinification experiments (Rossignol et al., 2003), with $100 \mathrm{~g} / \mathrm{L}$ of glucose and $100 \mathrm{~g} / \mathrm{L}$ of fructose.

To assess the relative growth of $S$. cerevisiae and other Saccharomyces species under winemaking conditions, we performed competition experiments in which we measured the relative amount of both strains in co-cultures. We included a $S$. cerevisiae strain, either T73 or YPS128, and a non cerevisiae one, in all these experiments and measured their relative abundance at different fermentation times. As controls, we monitored the growth of each strain in monocultures under the same conditions as the competitions experiments. Overnight precultures were grown in YPD medium at $25^{\circ} \mathrm{C}$. Afterward must was inoculated with the corresponding yeast strain to reach an initial concentration of $10^{6}$ cells $/ \mathrm{mL}$, and was incubated at a fixed temperature $\left(8,12,20\right.$, or $\left.25^{\circ} \mathrm{C}\right)$ with agitation at $100 \mathrm{rpm}$ during fermentation.

Cell samples were collected at several time points during fermentation and kept at $-20^{\circ} \mathrm{C}$ for the subsequent total DNA isolation, used for the QPCR analysis, as described below. Cell counting was carried out in a Neubauer chamber to determine cell density at every sampling point. Growth curves were obtained by considering cell density and the proportion of competing strains given by the QPCR data.

Müller valves were used to monitor fermentation stage through weight loss, until it reached a constant weight, when it was considered to be over. At this point, samples of supernatant were kept at $-20^{\circ} \mathrm{C}$ for further analyses.

\section{Primer Design}

Alignments of homologous chromosomes from $S$. cerevisiae S288c, S. paradoxus, S. kudriavzevii, and S. uvarum were carried out by the Mauve alignment tool (Darling et al., 2004). Genomic sequences were downloaded from the Saccharomyces Sensu Stricto Resources website (Scannell et al., 2011) and Saccharomyces Genome Database (Engel, 2013). By way of example, a SNPs map of the gene BUD3 of $S$. paradoxus, S. kudriavzevii, and S. uvarum individually aligned against $S$. cerevisiae is shown in Figure 1. This highly conserved single copy gene was selected to look for strain-specific pairs of primers (Supplementary Table 1). All the resulting amplicons were approximately $100 \mathrm{bp}$ in length and had a similar melting temperature when detected with our LightCycler $\left.{ }^{(}\right) 480$ II instrument.

\section{Specificity of the PCR Assays}

Total DNA samples were extracted from yeasts as described below. PCRs were carried out in a $20 \mu \mathrm{L}$ final volume, 


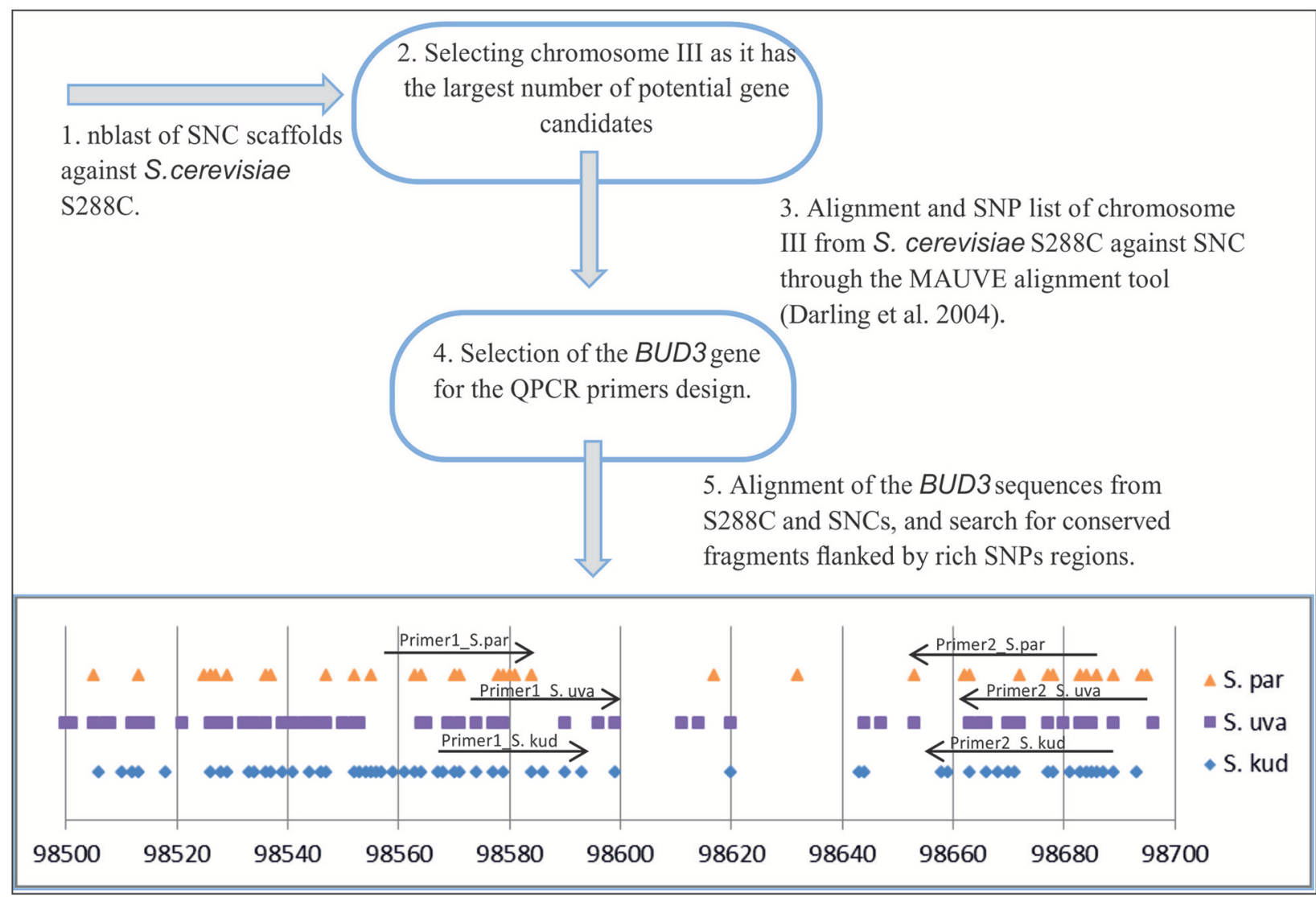

FIGURE 1 | Scheme used for QPCR primers design.

including $1 \mu \mathrm{L}$ of the DNA template, $0.25 \mu \mathrm{M}$ of each primer, $200 \mu \mathrm{M}$ of each dNTP, $2.5 \mathrm{mM}$ of $\mathrm{MgCl}_{2}, 10 \mathrm{X}$ buffer, and $0.75 \mathrm{U}$ of Taq DNA polymerase (Takara, Bio, Shiga, Japan). For each case, total DNA from the competitor strain was used as a crossed amplification control.

The PCR program consisted of an initial denaturalization step at $94^{\circ} \mathrm{C}$ for $5 \mathrm{~min}$, followed by 30 cycles of a denaturalization step at $94^{\circ} \mathrm{C}$, an annealing step at either 53 or $54^{\circ} \mathrm{C}$ for 1 min, and an extension step at $72^{\circ} \mathrm{C}$ for $10 \mathrm{~s}$, and a final extension step at $72^{\circ} \mathrm{C}$ for $5 \mathrm{~min}$. PCR products were analyzed by electrophoresis on a $1.5 \%(\mathrm{w} / \mathrm{v})$ agarose gel stained with RealSafe $^{\mathrm{TM}}$ nucleic acid staining solution (20,000X) (Chembio Diagnosis Systems, Medford, NY, USA) in 1x TAE buffer, and were visualized under UV light. A 100-bp DNA ladder marker (Invitrogen ${ }^{\mathrm{TM}}$, Carlsbad, CA, USA) was used as the size standard.

\section{DNA Extraction and Sample Preparation}

Total DNA samples from all the yeasts were extracted as described elsewhere (Querol et al., 1992). The concentration of the DNA samples was measured in a Nanodrop spectrophotometer ND-1000 (Nanodrop Technologies ${ }^{\mathrm{TM}}$, Wilmington, DE. USA) and adjusted to $20 \mathrm{ng} / \mu \mathrm{L}$.

\section{qPCR Analysis}

PCR amplification was performed in a $10 \mu \mathrm{L}$ final volume that contained $2.5 \mu \mathrm{L}$ of the DNA template, $1.5 \mu \mathrm{L}$ MilliQ water, 0.2 $\mu \mathrm{M}$ of each primer, and $5 \mu \mathrm{L}$ of LightCycler ${ }^{(C)} 480$ SYBR Green I Master (Roche). Reactions were performed in 96-well plates in an LightCycler ${ }^{\complement} 480$ (II) PCR amplification and detection instrument with an initial denaturalization step at $95^{\circ} \mathrm{C}$ for $5 \mathrm{~min}$, followed by 45 cycles of $95^{\circ} \mathrm{C}$ for $10 \mathrm{~s}$, either 53 or $54^{\circ} \mathrm{C}$ for $10 \mathrm{~s}$ and $72^{\circ} \mathrm{C}$ for $4 \mathrm{~s}$. The $C_{T}$ values were calculated automatically by this instrument.

Plates were always divided into two symmetric halves. In each one, a different reaction mix was used where the pair of primers was specific for one of the two strains. For each half, an internal standard curve was included, made of six serial dilutions of the mixed total DNA from both competing strains in 1:1 proportions, the total DNA from the strain amplified in this half as a positive control, the total DNA from the other strain in competition as a control for cross amplification, and a negative control with PCR grade water instead of the template DNA. Three to six biological replicates were used.

The relative concentration of both strains in each biological replicate was given by the ratio of the means of the technical replicates concentrations calculated by the LightCycler 480 instrument software 1.5 (Roche Diagnosis, Darmstadt, Germany). 


\section{Method Sensitivity}

For every competition experiment, the following test was performed to assess the reliability of our method. The mix of cells of the corresponding strains was prepared from overnight GPY precultures in known proportions (10:90, 30:70, 50:50, 70:30, and 90:10). The QPCR analysis was carried out using total DNA extraction samples from the mixes of cells. The relative concentration of both strains in each sample was given by the ratio of the means of the concentrations of the replicates given by the LightCycler 480 instrument software 1.5 (Roche Diagnosis, Darmstadt, Germany). Three biological replicates were included.

Linear model adjustments were made for the cell proportions estimated with each used pair of primers against the theoretical values, and for all the collected data as a whole. The function $\operatorname{lm}($ ) from $\mathrm{R}$ was used for this purpose.

\section{Relative Intrinsic Growth Rate Determination}

The intrinsic growth rate $(r)$ can be calculated as in a previous work of Williams et al. (2015). Here the same method was followed with some modifications:

$$
N_{t}=N_{0} e^{r t}
$$

where $N_{t}$ is cell density at a given time point, $N_{0}$ corresponds to the initial cell density, and $t$ is the time (in hours) when both strains reached their highest cell density in both competition and monoculture.

The effect that competition has on the involved strains can be assessed as the difference in their intrinsic growth rate in single culture and in competition $\left(\Delta=r_{\text {single }}-r_{\text {competition }}\right)$. For the sake of better clarifying the results, the relative intrinsic growth rate $\left(\mathrm{R} \Delta \mathrm{r}=\Delta \mathrm{r} / r_{\text {single }}\right)$ was determined.

\section{Growth Kinetics Parameters}

On day 1, the precultures of all the used strains were grown $\mathrm{o} / \mathrm{n}$ at $25^{\circ} \mathrm{C}$ in GPY medium. On day 2, cells were harvested by centrifugation, washed, suspended in $\mathrm{dH}_{2} \mathrm{O}$ and diluted to an $\mathrm{OD}_{600}$ of 2.7. Next $10 \mu \mathrm{L}$ from each dilution were pipetted into one well of a 96-well plate, previously filled with $260 \mu \mathrm{L}$ of SM (10 replicates). Four wells were filled with only sterile SM as a blank for the $\mathrm{OD}_{600}$ measurements. Four plates were set, one for each assayed temperature: $8,12,20$, and $25^{\circ} \mathrm{C}$.

$\mathrm{OD}_{600}$ was monitored in a SPECTROstar Omega instrument (BMG Labtech, Offenburg, Germany). Frequency of measurements varied according to temperature in order to obtain sufficient data points for a statistically significant adjustment to the reparametrized Gompertz equation proposed by Zwietering et al. (1990), which takes this expression:

$$
y=D \times \exp \{-\exp [((\mu \max \times e) / D) \times(\lambda-t)+1]\}
$$

where $y=\ln \left(\mathrm{OD}_{t} / \mathrm{OD}_{0}\right), \mathrm{OD}_{0}$ is the initial $\mathrm{OD}$ and $\mathrm{OD}_{t}$ is the OD at time $t, D$ is the asymptotic maximum, the equivalent to $\ln$ $\left(\mathrm{OD}_{\max } / \mathrm{OD}_{0}\right), \mu_{\max }$ is the maximum specific growth rate $\left(\mathrm{h}^{-1}\right)$ and $\lambda$ is the lag phase period (h). An adjustment was made using a nonlinear regression procedure of minimizing the sum of the squares of the difference between the experimental data and the fitted model. This was done using version 7.0 of the Statistica software (Stat-Soft, Inc., Tulsa, OK, USA).

Strains were tested for the significant differences among them with an ANOVA using the one-way ANOVA module of the Statistica 7.0 software. Growth parameters $\mu_{\max }$ and $\lambda$ were introduced as dependent variables. Means were grouped using the Tukey HSD test $(\alpha=0.05)$.

\section{Correlation of Relative Intrinsic Growth Rate and Growth Kinetics Parameters}

Linear regression models $\left(\mathrm{y}=\mathrm{Ax}_{1}+\mathrm{B}\right.$ and $\mathrm{y}=\mathrm{Ax}_{2}+$ B) were constructed, where $\mathrm{y}=R \Delta r$ for the non cerevisiae strain, $x_{1}=\left(\mu_{\max _{\text {competitor }}}-\mu_{\max _{\text {S. cerevisiae }}}\right) / \mu_{\max _{\text {competitor }}}(R \Delta \mu)$ and $\mathrm{x}_{2}=\left(\lambda_{\text {S. cerevisiae }}-\lambda_{\text {competitor }}\right) / \lambda_{\text {competitor }}(R \Delta \lambda)$. This was done using the R function $\operatorname{lm}$ (R Core Team, 2015).

\section{HPLC Analysis}

Residual sugars (glucose and fructose), glycerol, ethanol and acetic acid from the fermentation end point samples were determined by HPLC (Thermo Fisher Scientific, Waltham, MA. USA) using a refraction index detector and a HyperREZTM XP Carbohydrate $\mathrm{H}+8 \mu \mathrm{m}$ column (Thermo Fisher Scientific) equipped with a HyperREZTM XP Carbohydrate Guard (Thermo Fisher Scientific). Samples were diluted 3-fold, filtered through a $0.22-\mu \mathrm{m}$ nylon filter (Symta, Madrid, Spain) and injected in duplicate. The analysis conditions were: eluent, 1.5 $\mathrm{mM}$ of $\mathrm{H}_{2} \mathrm{SO}_{4} ; 0.6 \mathrm{ml} \mathrm{min}-1$ flux and a $50^{\circ} \mathrm{C}$ oven temperature.

\section{Statistical Analysis of the Fermentation Kinetics and HPLC Results}

The recorded mass loss of the fermentation flasks correlates with sugar consumption, which was taken into consideration to fit our curve to Gompertz equation (Zwietering et al., 1990) and obtain fermentation parameters $m$ (maximum sugar consumption rate, $\mathrm{g} \mathrm{L}^{-1} \mathrm{~h}^{-1}$ ), $l$ (lag phase period, $\mathrm{h}$ ) and $t_{90}$ (time taken to consume $90 \%$ of sugars, h) as in Pérez-Través et al. (2014).

Fermentations were tested for the significant differences among them with an ANOVA using the one-way ANOVA module of the Statistica 7.0 software. The concentrations of glucose, fructose, glycerol, ethanol and acetic acid obtained by HPLC, and the parameters $m, l$, and $t_{90}$ were introduced as the dependent variables. Means were grouped using the Tukey HSD test $(\alpha=0.05)$. The analysis was performed for each temperature condition used.

\section{RESULTS}

\section{Specificity and Sensitivity of the qPCR Assay}

Six pairs of primers were designed, one for each strain, except for the $S$. uvarum strains, which share primers. To check for specificity, primers were tested by conventional PCR amplification. Bands of the desired size were observed in all cases. Absence of bands from the PCR reactions of the total DNA isolated from the competitor strain confirmed strain specificity. 
To assess the technique's sensitivity for the relative quantification of different yeast strains in co-culture, mixes of cells in known proportions were prepared for each assayed competition; i.e., our reference $S$. cerevisiae winery strain T73 against S. kudriavzevii strain CR85, S. uvarum strain BMV58, S. uvarum strain CECT12600, S. paradoxus strain 54 or $S$. eubayanus strain NPCC1292, and the wild S. cerevisiae strain YPS128 against $S$. kudriavzevii strain CR85. The obtained QPCR results about the theoretical proportions can be seen in Figure 2. Data were fitted to linear regression models and coefficients that came very close to the normal for all cases were obtained (Table 1). These results were statistically significant according to the Fisher test (Table 1). Thus, the method is suitable for the quantification of the different Saccharomyces strains mixed in a culture.

\section{Yeast Competitions}

To assess the effect of competition at low temperature on the intrinsic growth rate $(r)$ of the SNC species, we performed a series of fermentations conducted by yeast strains $S$. paradoxus 54, S. uvarum BMV58, S. uvarum CECT12600, S. kudriavzevii CR85 and S. eubayanus NPCC1292 in competition with wine S. cerevisiae strain T73. We also tested the behavior of wild S. cerevisiae strain YPS128 in competition with S. kudriavzevii CR85. These competition experiments were performed in batch fermentations of SM at 8,12 , and $20^{\circ} \mathrm{C}$. Fermentations at a moderate temperature condition $\left(25^{\circ} \mathrm{C}\right)$ were also performed as a control of $S$. cerevisiae's imposition on cryotolerant yeasts. Monoculture fermentations, inoculated with the same strains, were performed as controls under the same conditions.

Figure 3 shows the percentages of the strains under competition when fermentation reached the stationary growth phase. These results offer an overview of the output of competitions during fermentation at different temperatures. We can see that wine $S$. cerevisiae T73 was able to exclude all the other Saccharomyces strains during fermentation at $25^{\circ} \mathrm{C}$. At $20^{\circ} \mathrm{C}$, T73 also outcompeted all the strains, except for wine $S$. uvarum BMV58, which was present in similar percentages. However, at low temperature, $12^{\circ} \mathrm{C}$, T73 co-existed with $S$. eubayanus, $S$. kudriavzevii and $S$. paradoxus, but was displaced by both the $S$. uvarum strains.

In the competitions between wild strains S. cerevisiae YPS128 and S. kudriavzevii CR85, YPS128 clearly outcompeted CR85 at $25^{\circ} \mathrm{C}$, they co-existed at $20^{\circ} \mathrm{C}$, but CR85 certainly dominated at low temperatures.

Despite these results being quite explicative about domination during competition, it is interesting to obtain a quantitative measurement of the effect that presence of a particular yeast can have on its competitor's growth. The most suitable indicator of these effects is the relative intrinsic growth rates $(R \Delta r)$ based on the difference of growth rates when the strain is grown in a mixed culture and in a single culture (Figure 4). It is important to note that there was no significant positive effect on the growth of any strain as a result of the presence of a competitor. For $S$. cerevisiae, these effects were negative at low temperatures, but null or insignificant at high temperatures (Figure 4). For $S$. uvarum and S. kudriavzevii, a trend in the opposite direction was noted as the effect was less negative (or insignificant) at low temperatures, and the negative effect increased with temperature (Figures 4C-F). Finally for S. paradoxus and S. eubayanus, the strongest negative effect occurred at medium temperature $\left(20^{\circ} \mathrm{C}\right)$ (Figures 4A,B).

The comparison made between the performances of strains of the same species, but with different origins, showed that S. cerevisiae T73 and S. uvarum BMV58 wine strains were considerably less affected by their competitors than the strains

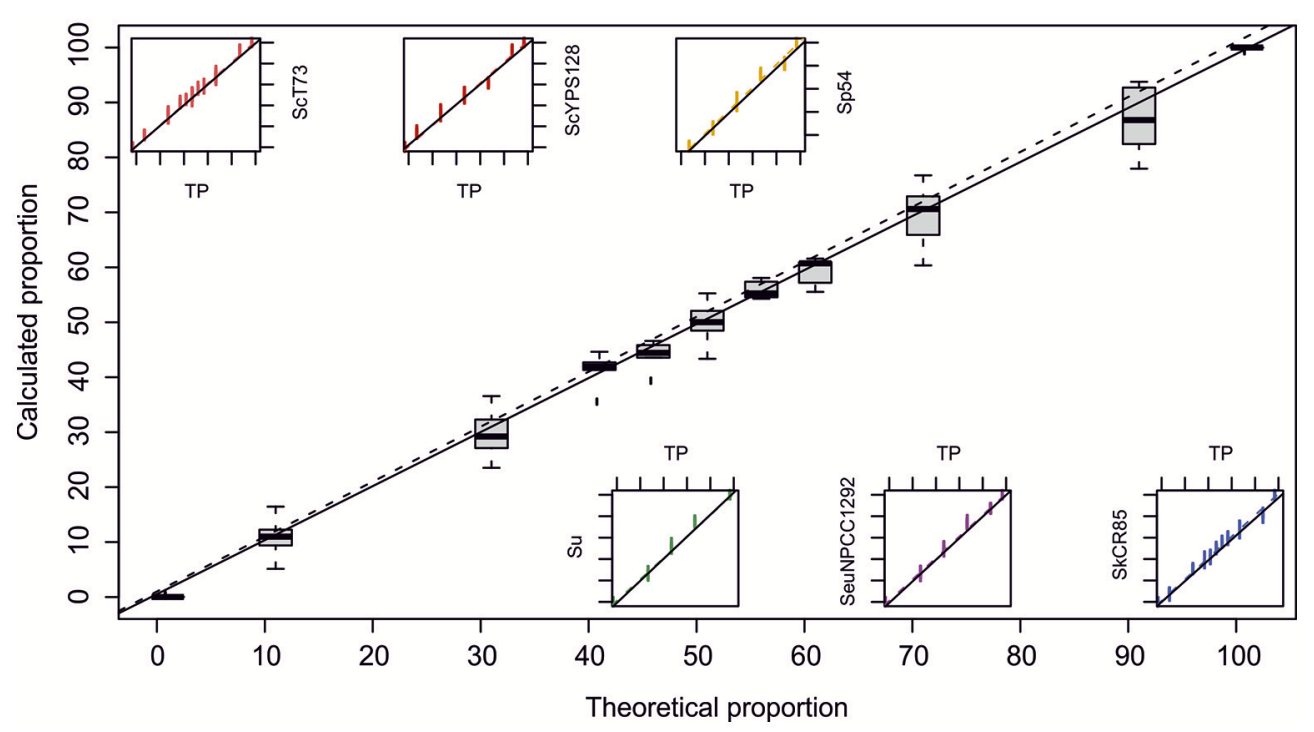

FIGURE 2 | Calculated relative quantification by QPCR against theoretical values. Boxplot shows the summary of all the data, while small graphics show the dispersion for each specific pair of primers. Data sets were adjusted to a linear model. Dotted lines represent normal distribution and full lines denote adjustments. 
TABLE 1 | Linear model adjustment results for the calculated relative QPCR quantification ( $y$ ) against the theoretical values $(X)$.

\begin{tabular}{lcccc}
\hline Pair of primers & A & B & R2 & p-value \\
\hline S. cerevisiae T73 & 1.0089 & -0.5715 & 0.9924 & $<2.2 \times 10-16$ \\
S. paradoxus 54 & 1.0074 & 1.2536 & 0.9829 & $1.473 \times 10-15$ \\
S. eubayanus NPCC1292 & 0.9834 & 1.4564 & 0.9905 & $<2.2 \times 10-16$ \\
S. uvarum BMV58/CECT12600 & 0.9640 & 1.2897 & 0.9924 & $3.655 \times 10-15$ \\
S. cerevisiaeYPS128 & 1.0214 & -1.6341 & 0.9867 & $<2.2 \times 10-16$ \\
S. kudriavzevii CR85 & 1.0182 & 0.5339 & 0.9905 & $<2.2 \times 10-16$ \\
\hline All & 10060 & 0.043 & 0.9889 & $<2.2 \times 10-16$
\end{tabular}

$A$, is the regression coefficient and $B$, is the error term. p-values are obtained by the Fisher test.

with other origins, such as S. cerevisiae YPS128 and S. uvarum CECT12600 (Figures 4C-F).

Prevalence during fermentation seemed to be clearly related to temperature adaptation. The correlations of growth parameters maximum growth rate and lag phase duration (Table 2) with the relative increment in the intrinsic growth rate were calculated. Positive correlations with $\mathrm{R}^{2} \sim 0.4$ were obtained for both parameters.

\section{Competitions between S. cerevisiae T73 and S. paradoxus 54}

When competing with $S$. paradoxus strain 54, T73 achieved slightly lower intrinsic growth rate at $12^{\circ} \mathrm{C}$ compared to a single fermentation. However, at 20 and $25^{\circ} \mathrm{C}$, its growth fitness is maintained (Figure 4A). Strain 54 performed normally at low temperature, but was clearly affected at 20 and $25^{\circ} \mathrm{C}$ (Figure 4A), and was almost totally excluded from fermentation (Figure 3). Although both species were phylogenetically closely related, the wine $S$. cerevisiae strain seemed superior in this competition. Furthermore, it is interesting to note that at all tested temperatures, the dominant strain T73 had a shorter lag phase ( $\lambda$, Table 2).

\section{Competitions between S. cerevisiae T73 and S. eubayanus NPCC1292}

In competition both strains maintained their capability to grow in co-cultures at 12 and $25^{\circ} \mathrm{C}$, according to the slight drop in their intrinsic growth rate parameter compared to single cultures. Strikingly at intermediate temperatures, NPCC1292 was clearly outcompeted by T73 (Figure 4B), when its lag phase became noticeably longer (Table 2). Although the intrinsic growth rate of NPCC 1292 was only slightly affected at $25^{\circ} \mathrm{C}$, this strain was present at a low percentage during fermentation (Figure 3). This can be explained by a low cell density during not only competition, but also during single culture fermentation (data not shown).

\section{Competitions between S. cerevisiae T73 and S. uvarum strains}

Here we assessed the competitive adaptation capacity of a wine and a non fermentative $S$. uvarum. Wine $S$. uvarum strain

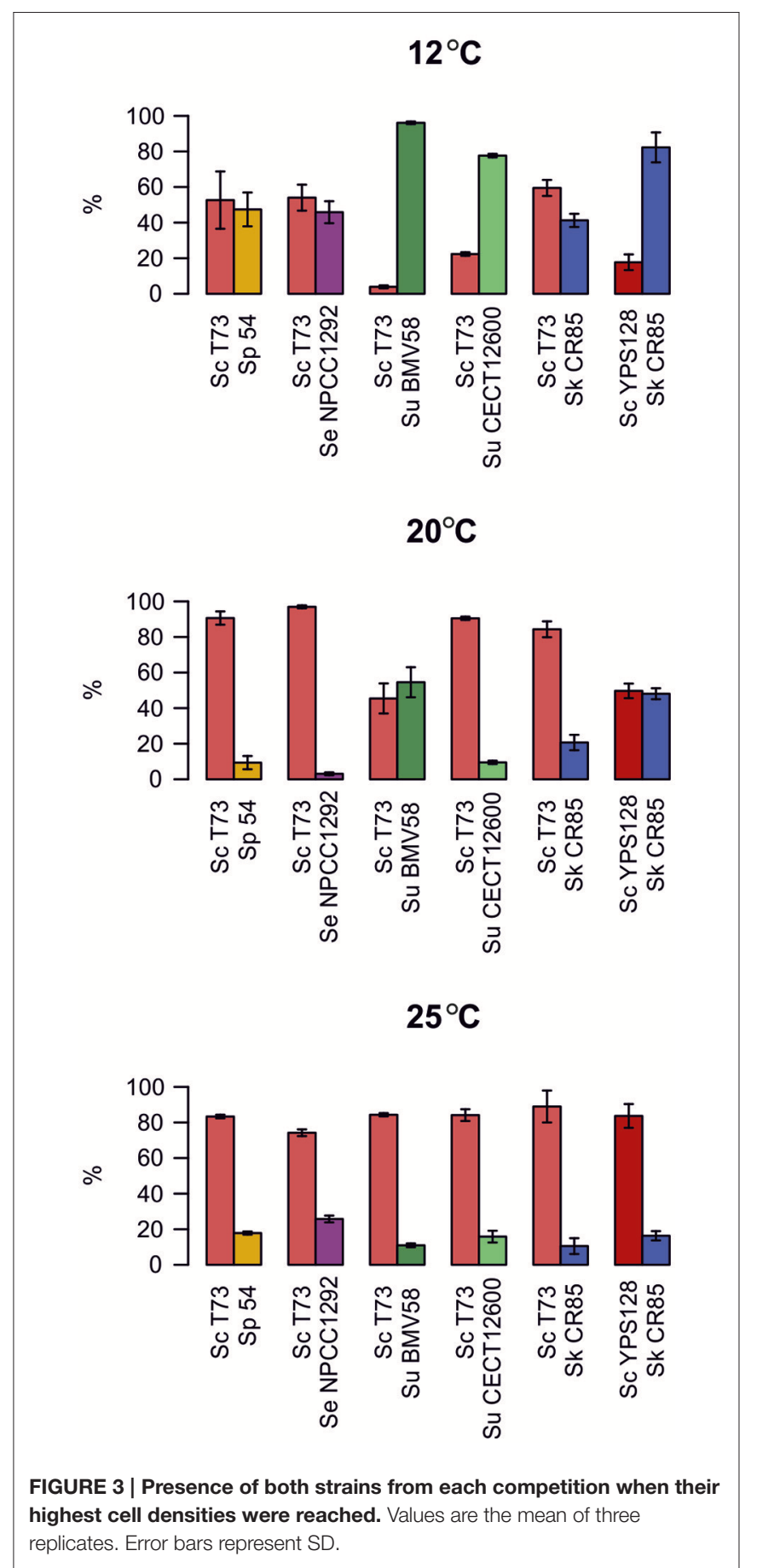

BMV58 competed better at low temperatures $\left(12\right.$ and $\left.20^{\circ} \mathrm{C}\right)$, and severely affected $\mathrm{T} 73$ growth. This effect reverted as temperature rose. We can see that $\mathrm{T} 73$ shows a clear advantage at $25^{\circ} \mathrm{C}$ (Figure 4C).

To test whether the same trend could be observed with a non wine strain, we performed the same experiment using strain S. uvarum CECT12600. The behavior of the differential intrinsic growth rates was similar, but in this case $S$. uvarum CECT12600 obtained lower values and had a less intense effect on 

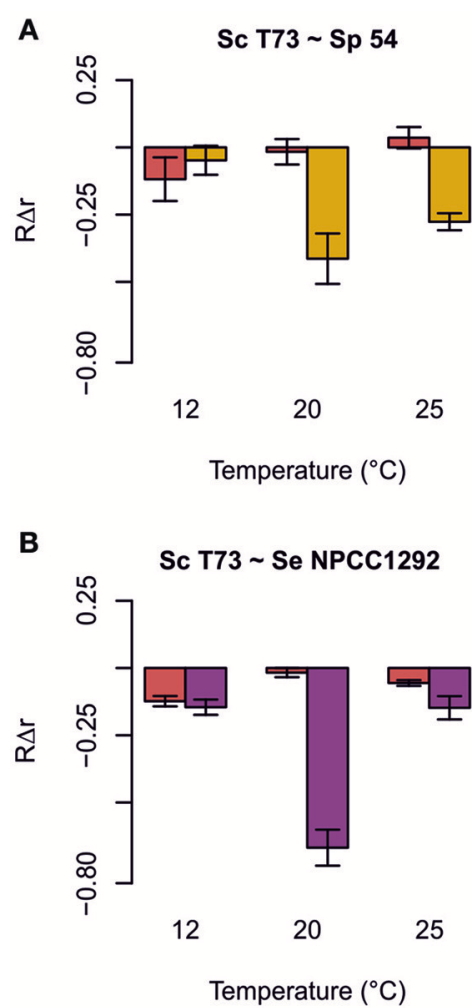
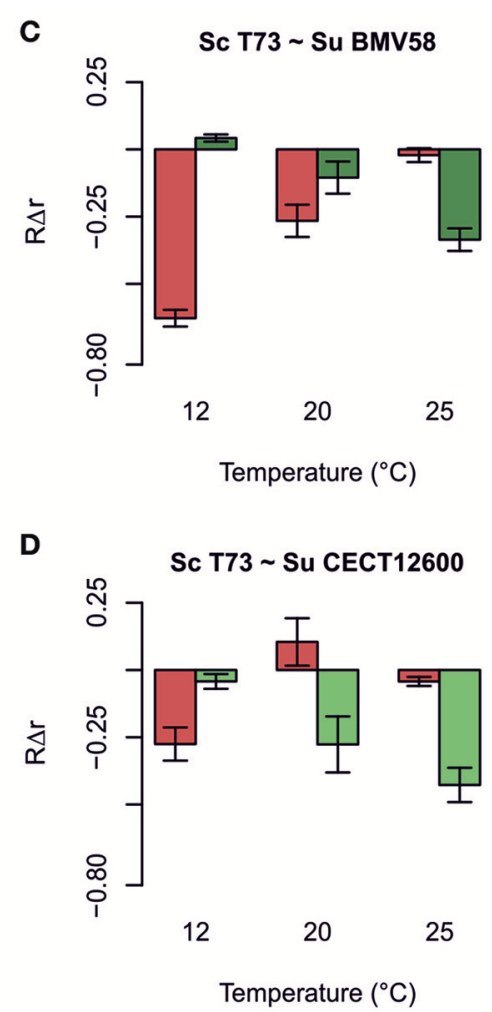
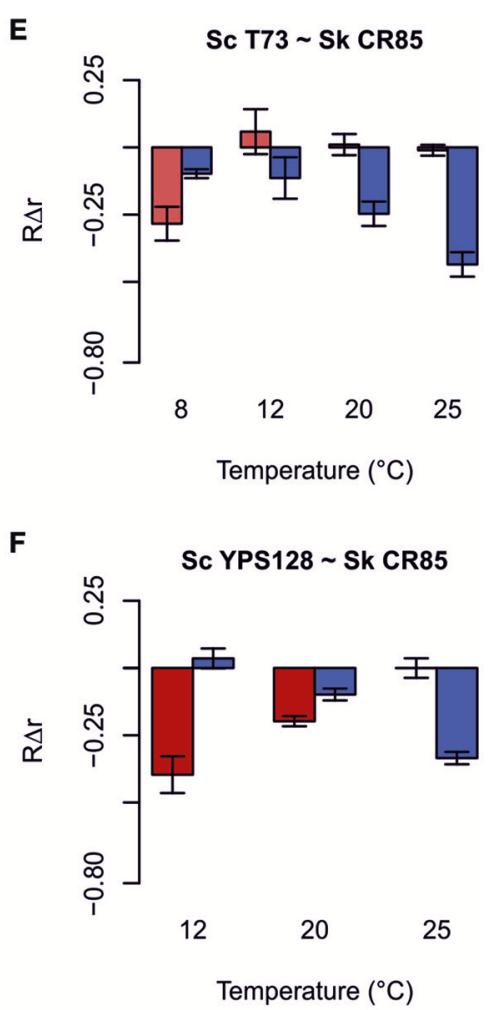

FIGURE 4 | Relative intrinsic growth rate $\left(\mathrm{R} \Delta \mathrm{r}=\left(\boldsymbol{r}_{\text {competition }}-\boldsymbol{r}_{\text {single }}\right) / \boldsymbol{r}_{\text {single }}\right)$ caused by the effect of competitions between Saccharomyces cerevisiae T73 and S. paradoxus 54 (A), S. cerevisiae T73 and S. eubayanus NPCC1292 (B), S. cerevisiae T73 and S. uvarum BMV58 (C), S. cerevisiae T73 and S. uvarum CECT12600 (D), S. cerevisiae T73 and S. kudriavzevii CR85 (E), and S. cerevisiae YPS128 and S. kudriavzevii CR85 (F). Values are the means of triplicate experiments. Error bars represent SD.

T73 (Figure 4D) than BMV58, which showed better competitive fitness in fermentative environments.

Finally, it is important to remark that S. cerevisiae T73 had a shorter lag phase $(\lambda)$ than $S$. uvarum BMV58 during the competitions at 20 and $25^{\circ} \mathrm{C}$ (Table 2), but at similar maximum growth rates $\left(\mu_{\max }\right)$, and BMV58 was able to co-exist with T73 during the competition at $20^{\circ} \mathrm{C}$, but not at $25^{\circ} \mathrm{C}$ (Figure 4). At $12^{\circ} \mathrm{C}$, both $S$. uvarum strains had a shorter lag phase and higher maximum growth rates than $S$. cerevisiae (Table 2), and were dominant during fermentation (Figure 3).

\section{Competitions between S. kudriavzevii CR85 and S. cerevisiae strains}

Wine strain S. cerevisiae T73 is not affected by most temperature conditions when competing with S. kudriavzevii. However, at $8^{\circ} \mathrm{C}$, a clear negative effect on the relative intrinsic growth rate $(r)$ on T73 can be observed. S. kudriavzevii CR85 was always affected by presence of T73, although its impact was softer at $8^{\circ} \mathrm{C}$ and $S$. kudriavzevii became more competitive (Figure 4E).

To test if T73 resistance during competition, even at a very low temperature, was to some extent dependent on its better adaptation to fermentation environments, the wild $S$. cerevisiae strain YPS128, isolated from an oak bark, was used in the competitions assays with $S$. kudriavzevii. Figure $4 \mathbf{F}$ shows noticeable differences in the competition at $12^{\circ} \mathrm{C}$, where CR85 clearly outcompetes YPS128, and it exhibited an intrinsic growth rate that was markedly affected. In the competitions at $20^{\circ} \mathrm{C}$, in which S. kudriavzevii predominated (Figure 3), YPS128 underwent a greater negative effect (Figure 4). Contrarily at $25^{\circ} \mathrm{C}$, CR85 was clear at a disadvantage (Figure 4F). Therefore, the fermentative origin of the $S$. cerevisiae yeasts seems to correlate with better performance in fermentation.

The growth parameters from Table 2 could explain most of these results. At $8^{\circ} \mathrm{C}$, when $S$. Kudriavzevii outcompeted $S$. cerevisiae T73, the winner (Figure 3) had a higher maximum growth rate and a shorter lag phase. At $12^{\circ} \mathrm{C}$, S. kudriavzevii presented a shorter lag phase than both the $S$. cerevisiae strains, and a higher maximum growth rate than the wild $S$. cerevisiae strain, which was clearly affected under these conditions (Figure 4F). S. cerevisiae wine strain $\mathrm{T} 73$ had a clearly higher $\mu$ at $12^{\circ} \mathrm{C}$, which could be the reason why T73 became dominant as fermentation continued (Figure 3). At $20^{\circ} \mathrm{C}$, both the $S$. cerevisiae strains already exhibited better growth capabilities in synthetic must (Table 2), but there were clear differences in their performance during the competition against $S$. kudriavzevii as the wine strain was a much better competitor than the wild strain (Figures 3, 4E,F). 


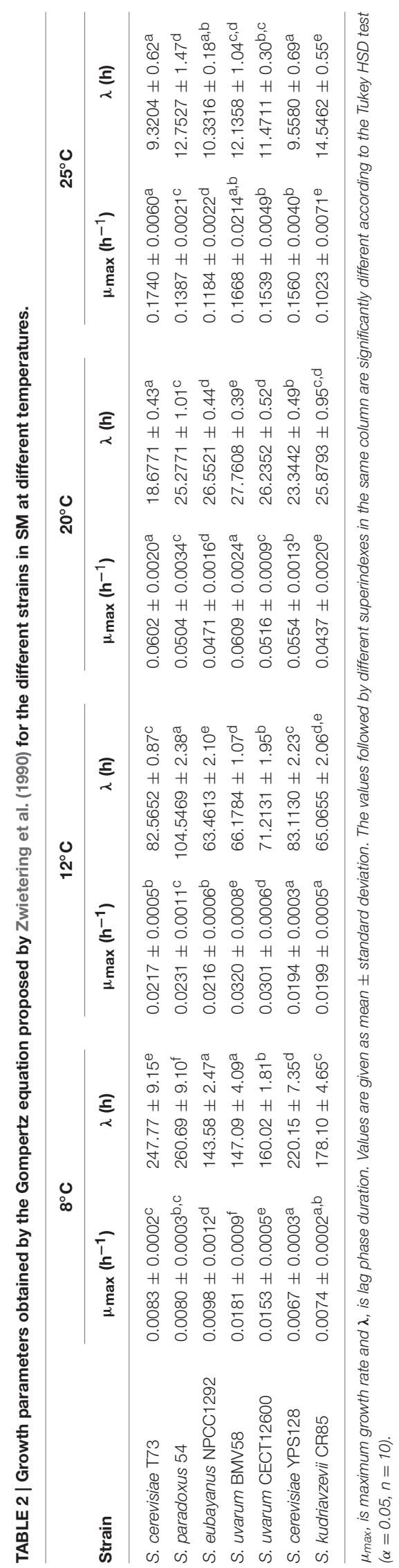

\section{Correlation between Growth Parameters and Competitive Advantage}

We assessed whether there was any correlation between the fact of having better growth parameters in single culture and the imposition during our competition experiments (Table 2). Linear correlations between $\mathrm{R} \Delta \mathrm{r}$ and $\mathrm{R} \Delta \mu$ or $\mathrm{R} \Delta \lambda$ were obtained, with $R^{2}$-values of 0.40 and 0.42 , respectively. Significance was tested by the Fisher's test, and the resulting $p$-values were 0.005158 and 0.003681 , respectively.

A graphical summary of the three parameters used in the analysis for each competition is depicted in Figure 5. In most cases, low $\mathrm{R} \Delta \mathrm{r}$ values corresponded to low $\mathrm{R} \Delta \mu$ and $\mathrm{R} \Delta \lambda$. This indicates that a more affected strain during co-fermentations exhibits worse growth parameters in single culture than its competitor (Figure 4, Table 2).

There are some exceptions however, as already mentioned above, such as the competition between T73 and BMV58 at $20^{\circ} \mathrm{C}$, at which $S$. uvarum had a similar $\mathrm{R} \Delta \mu$ and a notably worse $\mathrm{R} \Delta \lambda$ value, but competition had a remarkably negative effect on $S$. cerevisiae. Interestingly, Figure 5 shows comparatively slight $\mathrm{R} \Delta \mu$ or $\mathrm{R} \Delta \lambda$ differences together with extreme $\mathrm{R} \Delta \mathrm{r}$ values (T73NPCC1292, $20^{\circ} \mathrm{C}$ ), and vice versa (T73-NPCC1292, $25^{\circ} \mathrm{C}$ ). This indicates that co-culture fermentations may be influenced by other competitive growth strategies.

\section{Influence of Competition on Fermentation Parameters}

Yeast characterization as wine fermenters must include aspects like the ability to consume all the sugars present in must at a suitable pace, or the capability to produce a wine with high quality standards according to consumer demands. Table 3 includes different fermentation kinetic parameters: maximum sugar consumption rate $(m)$ and fermentation lag phase $(l)$, inferred from mass loss during fermentation, as well as the time taken to consume $90 \%$ of the initial sugar content $\left(t_{90}\right)$. Final product composition is also a key factor. Thus, we measured glucose, fructose, glycerol and ethanol concentrations at the end of fermentation, that is, when no mass loss was observed (Table 4). This data set is useful to determine the mixed yeast cultures that could potentially improve some wine characteristics.

Reference wine strain S. cerevisiae T73 is characterized by the production of relatively low glycerol values $\left(5-6 \mathrm{~g} \mathrm{~L}^{-1}\right)$ and high ethanol content (>12\%), as observed in Table 4. It also accomplishes quite a high sugar consumption rate at $20^{\circ} \mathrm{C}$ (Table 3) and $25^{\circ} \mathrm{C}$ (Table 3), but a low one at $12^{\circ} \mathrm{C}$ (Table 3), which is consistent with the temperature adaptation of S. cerevisiae to grow at higher temperatures than cryotolerant species $S$. uvarum and S. kudriavzevii. In most cases, and according to the ANOVA analysis, its $l$ and $t_{90}$ belong to the group of the shortest times (Table 3 ).

Interestingly, some co-cultures improved these fermentation parameters; e.g., T73 with either S. kudriavzevii CR85 or S. uvarum BMV58 at $12^{\circ} \mathrm{C}$ increased the $m$, and reduced $t_{90}$ (Table 3). At $25^{\circ} \mathrm{C}$, the combinations of T73 with S. kudriavzevii and $S$. uvarum once again seemed to improve the fermentation kinetics. A reduction of $t_{90}$ for the three co-cultures (T73-CR85, 


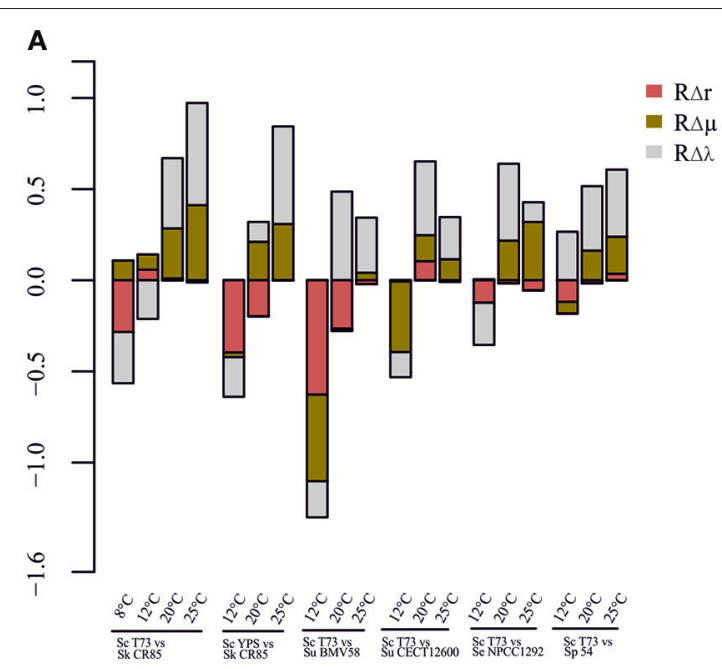

B

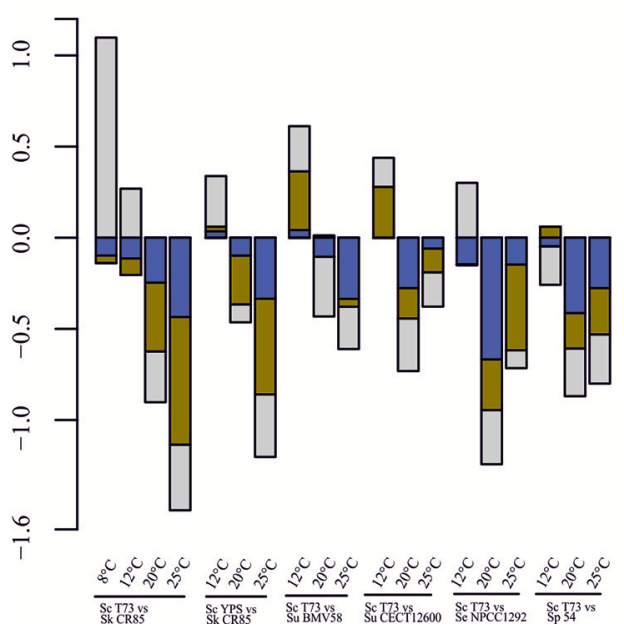

FIGURE 5 | Comparative of performance in competition and growth kinetics parameters in single culture for $\mathbf{S}$. cerevisiae (A) and competitor strains (B).

T73-BMV58 and T73-CECT12600) was also observed at $25^{\circ} \mathrm{C}$ (Table 3). These fermentation parameters improved compared to their respective single culture fermentations (Table 3), which is indicative of synergic interactions.

Unlike the 12 and $25^{\circ} \mathrm{C}$ conditions, practically no fermentation parameters or compounds improved at $20^{\circ} \mathrm{C}$ (Tables 3, 4). The competitions against $S$. paradoxus seemed disadvantageous at $20^{\circ} \mathrm{C}$ and $25^{\circ} \mathrm{C}$, which also occurred when competing with $\mathrm{CR} 85$ at $20^{\circ} \mathrm{C}$ and with NPCC 1292 at $25^{\circ} \mathrm{C}$ (Table 3).

Despite their diverse origins, all the strains were able to complete their fermentations at $25^{\circ} \mathrm{C}$ except $S$. eubayanus NPCC1292 (Table 4). By the end of the fermentations conducted by this strain, the final product contained large amounts of glucose, and especially fructose. At low and medium temperatures $\left(12\right.$ and $20^{\circ} \mathrm{C}$ ) some strains also left a considerable amount of sugars, such as S. cerevisiae YPS128 or competences NPCC1292-T73, CECT12600-T73, 54-T73 and CR85-YPS128 (Table 4). Interestingly, most of them were able to ferment all the sugars when cultured alone (Table 4), so this could result in an antagonist effect for these pairs of strains. Moreover, some other parameters also reflected worse performances during cofermentations, specifically $t 90$ of T73-NPCC 1292 at $12^{\circ} \mathrm{C}$, or T73-54 and T73-CECT12600 at $20^{\circ} \mathrm{C}$ (Table 3).

As previously mentioned, a more profitable interaction is observed for CR85-T73 at low temperatures. At $12^{\circ} \mathrm{C}$ both strains co-existed during fermentation in similar proportions (Figure 3), which led to a final product with a lower ethanol concentration and a higher glycerol content than those obtained for the fermentations conducted by T73 alone (Table 4). Ethanol concentrations also lowered during co-inoculated fermentations at 20 and at $25^{\circ} \mathrm{C}$, but the conservative ANOVA test did not support the significance of these differences (Table 4). With the co-cultures of T73 with S. uvarum, no significant improvements in the final product composition were observed, although mean glycerol values and ethanol concentrations showed a positive tendency compared to the single $S$. cerevisiae fermentations at 12 and $20^{\circ} \mathrm{C}$ (Table 4).

\section{DISCUSSION}

\section{Accurate Quantification of Different Saccharomyces Yeasts in Co-cultures}

Natural auxotrophic or drug-resistant mutants and strains genetically modified with reporter genes have been used to monitor yeast competences in co-cultures or during fermentation, which involves demanding tasks, such as mutant selection or construction, CFU enumeration in selective media, or flow cytometry (Arroyo-López et al., 2011; García-Ríos et al., 2014). Our results indicate that a more straightforward QPCR-based method, which does not require previous cell type separation, is suitable for the relative quantification of yeasts (Figure 2). In fact quantification by QPCR of different organisms in wine, including Saccharomyces yeasts, has already been applied (Neeley et al., 2005; Andorrà et al., 2010; Vendrame et al., 2014). However, to our knowledge, this technique has never been used to date to differentiate Saccharomyces yeasts during competition in the same environment. This novel approach can be applicable to broaden our knowledge about the ecology of the Saccharomyces yeast when competing for the same niche.

\section{Temperature Adaptation Affects Domination in a Fermentative Environment}

Cryotolerant species S. kudriavzevii and S. uvarum have been used in this work given the trend to perform fermentation at lower temperatures in the wine industry to preserve the aroma fraction (Torija et al., 2001; Beltran et al., 2002; Gamero et al., 2013; Şener and Yildirim, 2013). Our results clearly show a longer prevalence of these species in fermentations at low temperatures. However, at $25^{\circ} \mathrm{C}, \mathrm{S}$. cerevisiae outgrow them. It can also be drawn from our data that this effect is modulated by 


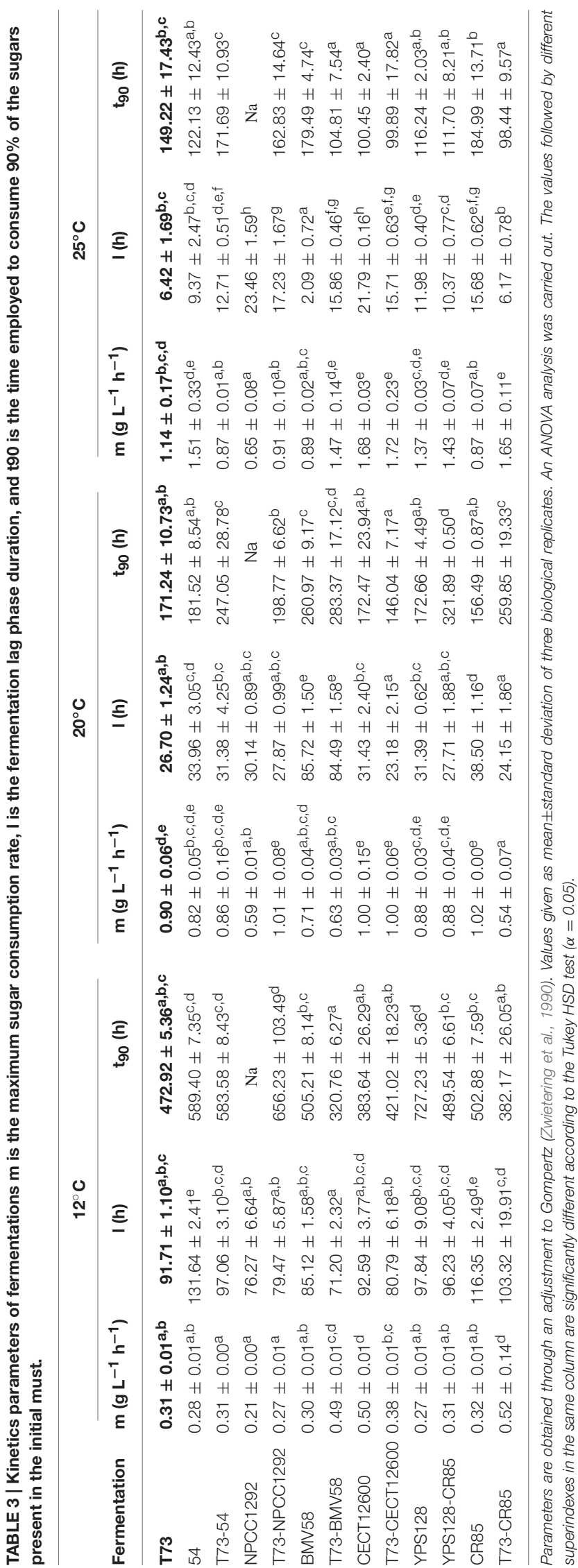

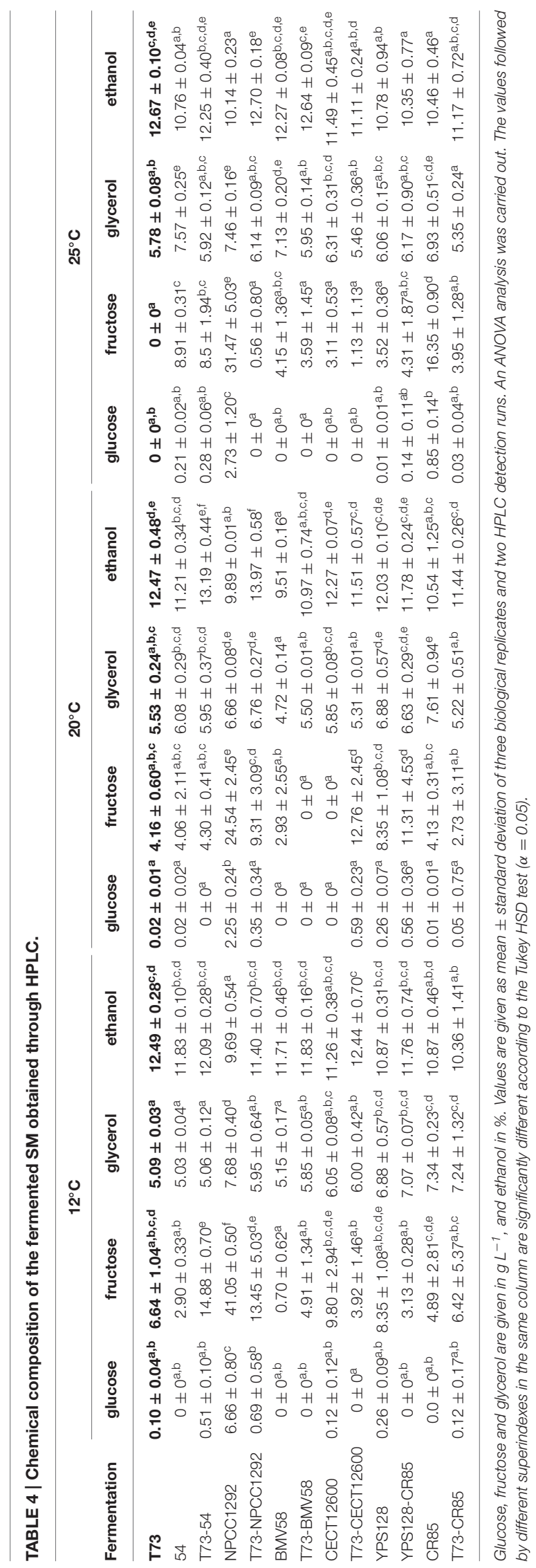


the adaptation of strains to different habitats, where wine strains are always more competitive no matter what the temperature. This was observed not only for $S$. cerevisiae, but also for $S$. uvarum. Therefore, adaptation to high sugar environments could be another trait that influences fermentation domination as indicated by Barrajón et al. (2011).

Salvadó et al. (2011b) analyzed the thermotolerance of different Saccharomyces species using their growth kinetics parameters as measurable indicators. Growth ability under settled conditions could be considered as a suitable predictor for the imposition of one strain on another in competition. However, previous works (García-Ríos et al., 2014), as well as ours, have revealed that domination of environments is a more complex trait on Saccharomyces yeasts. Figure 5 shows that in most cases a higher $\mu_{\max }$ and a lower $\lambda$ correlate to greater invulnerability in co-fermentation than the competitor strain. Nevertheless, we observed that the intensity of the effect is widely variable, and in some cases we found that the contrary happens; i.e., $S$. eubayanus NPCC1292 in the competition against S. cerevisiae $\mathrm{T} 73$ at $12^{\circ} \mathrm{C}$, whose growth was affected despite having a shorter lag phase. S. cerevisiae YPS128, a strain isolated from oak trees, performed worse than expected against $S$. kudriavzevii CR85 at $20^{\circ} \mathrm{C}$. Something similar occurred with the competition between S. cerevisiae T73 and S. uvarum BMV58 for both wine strains at $20^{\circ} \mathrm{C}$ : T73 had a noticeably shorter $\lambda$ and a similar $\mu_{\max }$, but was clearly wakened by BMV58. Thus, it is conceivable that an interaction among yeasts or their side products takes place as part of the competition mechanism. Whether this means that the presence of toxic compounds targets some specific Saccharomyces yeasts, the inhibitory physical contact among them, or some other strategy, is something that needs to be looked at in the future.

\section{Coinoculation of Saccharomyces Yeasts Can Be Potentially Beneficial for Fermentations and Final Product Composition}

One of the main goals when studying alternative organisms for their use in food fermentation is achieving new characteristics of interest, that these organisms give rise to. With wine, numerous studies have been carried out with non Saccharomyces yeasts, and most have focuses on improving or enriching of aroma profiles, whereas others have focused more on controlling the final product concentration of specific compounds, such as ethanol or acetic acid (Andorrà et al., 2012; Rantsiou et al., 2012; Medina et al., 2013; Contreras et al., 2014; Izquierdo Cañas et al., 2014; Zara et al., 2014; Canonico et al., 2015, 2016; Rodrigues et al., 2016). However, fewer studies have been published about fermentation characterization by combining Saccharomyces strains or using uncommon Saccharomyces species (Cheraiti et al., 2005; Howell et al., 2006; King et al., 2010; ArroyoLópez et al., 2011; Barrajón et al., 2011; Saberi et al., 2012; Williams et al., 2015; Gustafsson et al., 2016). Just as some of these investigations have suggested, our results showed that the final product composition of co-fermented musts cannot always be predicted from those of mono-fermentations. We observed a range of different scenarios: synergic or antagonist effects, as well as simply additive, depending on the strains and the assayed conditions. Nevertheless, we found some promising combinations of a wine $S$. cerevisiae strain with a SNC one; e.g., the remarkable case of the co-inoculation of S. cerevisiae T73 and S. kudriavzevii CR85 at low temperatures, which improved the efficiency of the process as regards single inoculations by increasing the maximum sugar consumption rate, and which also yielded a final product that contained less ethanol and more glycerol.

From the kinetics point of view, the co-fermentations of our wine $S$. cerevisiae strain with $S$. uvarum also revealed a positive effect, which was more visible at 12 and $25^{\circ} \mathrm{C}$. This kind of synergic effect has been observed in previous works, where the addition of fructophilic yeast S. bombicola (similarly to $S$. uvarum) led to faster fructose and glucose consumption (Milanovic et al., 2012). In our case it was also noteworthy that the viability of T73 during competition against wine strain BMV58 was negatively influenced. However, against non winery strain CECT12600, it did not diminish, which means that winery strains could be more capable of sensing other yeasts in fermentative media and over-activate sugar consumption to take advantage of them. This hypothesis would also be supported by our results about the maximum sugar consumption rate $(\mathrm{m})$ of the co-fermentations carried out by our reference wine strains S. cerevisiae T73 with S. uvarum or S. kudriavzevii. At any rate it is remarkable that reduced $t_{90}$ values occurred during the fermentations run at $25^{\circ} \mathrm{C}$ for the cases of T73-CR85, T73BMV58 and T73-CECT12600, when SNC strains were present in small proportions. This could be indicating that S. cerevisiae T73 responded to interactions during competences by increasing its metabolism.

To summarize, we have confirmed the great capacity of $S$. cerevisiae to dominate fermentative environments at traditional process temperatures (Holm Hansen et al., 2001; Pérez-Nevado et al., 2006; Arroyo-López et al., 2011; Williams et al., 2015). However, some cryotolerant Saccharomyces yeasts, particularly S. uvarum, can seriously compromise $S$. cerevisiae fitness during competences at lower temperatures, which explains why $S$. uvarum can replace $S$. cerevisiae during wine fermentations in European regions with oceanic and continental climates (Naumov et al., 2000; Sipiczki et al., 2001; Naumov et al., 2002; Redžepović et al., 2002; Rementeria, 2003; Demuyter et al., 2004). From a biotechnological point of view, the application of cryotolerant Saccharomyces species as starters for wine fermentation at low temperature could avoid its colonization by undesirable microorganisms that has been reported by other authors (Ciani and Comitini, 2006).

Our results also suggest that adaptation to winemaking establishes noticeable differences in the performance of Saccharomyces yeasts when competing during wine fermentation. Thus, profounder research on Saccharomyces yeasts' physical and biochemical interactions is necessary to optimize the composition of such starter cultures, which would make them even more interesting for industrial purposes. As a hint, at low temperatures we obtained improvements in the final composition of important compounds, such as higher 
glycerol contents and a lower ethanol yield, as well as the better fermentation performance of some yeast combinations, especially those of the S. cerevisiae with cryotolerant SNC species.

\section{AUTHOR CONTRIBUTIONS}

JA, EB, and AQ conceived and designed the experiments. JA and ML performed the experiments. JA, EB, and AQ analyzed the data and wrote the paper.

\section{FUNDING}

JA was supported by a FPI grant from the Ministerio de Economía y Competitividad (ref. BES-2013-066434). This work

\section{REFERENCES}

Albergaria, H., and Arneborg, N. (2016). Dominance of Saccharomyces cerevisiae in alcoholic fermentation processes: role of physiological fitness and microbial interactions. Appl. Microbiol. Biotechnol. 100, 2035-2046. doi: 10.1007/s00253-015-7255-0

Albergaria, H., Francisco, D., Gori, K., Arneborg, N., and Gírio, F. (2010). Saccharomyces cerevisiae CCMI 885 secretes peptides that inhibit the growth of some non-Saccharomyces wine-related strains. Appl. Microbiol. Biotechnol. 86, 965-972. doi: 10.1007/s00253-009-2409-6

Andorrà, I., Berradre, M., Mas, A., Esteve-Zarzoso, B., and Guillamón, J. M. (2012). Effect of mixed culture fermentations on yeast populations and aroma profile. LWT-Food Sci. Technol. 49, 8-13. doi: 10.1016/j.lwt.2012.04.008

Andorrà, I., Esteve-Zarzoso, B., Guillamón, J. M., and Mas, A. (2010). Determination of viable wine yeast using DNA binding dyes and quantitative PCR. Int. J. Food Microbiol. 144, 257-262. doi: 10.1016/j.ijfoodmicro.2010.10.003

Antunovics, Z., Irinyi, L., and Sipiczki, M. (2005). Combined application of methods to taxonomic identification of Saccharomyces strains in fermenting botrytized grape must. J. Appl. Microbiol. 98, 971-979. doi: 10.1111/j.1365-2672.2005.02543.x

Arneborg, N., Siegumfeldt, H., Andersen, G. H., Nissen, P., Daria, V. R., Rodrigo, P. J., et al. (2005). Interactive optical trapping shows that confinement is a determinant of growth in a mixed yeast culture. FEMS Microbiol. Lett. 245, 155-159. doi: 10.1016/j.femsle.2005.03.008

Arroyo-López, F. N., Pérez-Torrado, R., Querol, A., and Barrio, E. (2010). Modulation of the glycerol and ethanol syntheses in the yeast Saccharomyces kudriavzevii differs from that exhibited by Saccharomyces cerevisiae and their hybrid. Food Microbiol. 27, 628-637. doi: 10.1016/j.fm.2010. 02.001

Arroyo-López, F. N., Pérez-Través, L., Querol, A., and Barrio, E. (2011). Exclusion of Saccharomyces kudriavzevii from a wine model system mediated by Saccharomyces cerevisiae. Yeast 28, 423-435. doi: 10.1002/yea.1848

Barrajón, N., Arévalo-Villena, M., Úbeda, J., and Briones, A. (2011). Enological properties in wild and commercial Saccharomyces cerevisiae yeasts: relationship with competition during alcoholic fermentation. World J. Microbiol. Biotechnol. 27, 2703-2710. doi: 10.1007/s11274-011-0744-0

Beltran, G., Torija, M. J., Novo, M., Ferrer, N., Poblet, M., Guillamón, J. M., et al. (2002). Analysis of yeast populations during alcoholic fermentation: a six year follow-up study. Syst. Appl. Microbiol. 25, 287-293. doi: 10.1078/0723-2020-00097

Branco, P., Francisco, D., Chambon, C., Hébraud, M., Arneborg, N., Almeida, M. G., et al. (2014). Identification of novel GAPDH-derived antimicrobial peptides secreted by Saccharomyces cerevisiae and involved in wine microbial interactions. Appl. Microbiol. Biotechnol. 98, 843-853. doi: 10.1007/s00253-013-5411-y

Canonico, L., Agarbati, A., Comitini, F., and Ciani, M. (2016). Torulaspora delbrueckii in the brewing process: a new approach to enhance was supported by grants AGL2012-39937-C02-01 and AGL201567504-C3-1-R from the Spanish Government and FEDER to AQ, AGL2012-39937-C02-02 and AGL2015-67504-C3-3-R from the Spanish Government and FEDER to EB, and PROMETEO (project PROMETEOII/2014/042) from Generalitat Valenciana to AQ. We acknowledge support of the publication fee by the CSIC Open Access Publication Support Initiative through its Unit of Information Resources for Research (URICI).

\section{SUPPLEMENTARY MATERIAL}

The Supplementary Material for this article can be found online at: http://journal.frontiersin.org/article/10.3389/fmicb. 2017.00150/full\#supplementary-material bioflavour and to reduce ethanol content. Food Microbiol. 56, 45-51. doi: $10.1016 /$ j.fm.2015.12.005

Canonico, L., Comitini, F., and Ciani, M. (2015). Influence of vintage and selected starter on Torulaspora delbrueckii/Saccharomyces cerevisiae sequential fermentation. Eur. Food Res. Technol. 241, 827-833. doi: 10.1007/s00217-015-2507-x

Cheraiti, N., Cheraiti, N., Salmon, J., Guezenec, S., and Salmon, J. (2005). Redox interactions between. Appl. Environ. Microbiol. 71, 255-260. doi: 10.1128/AEM.71.1.255-260.2005

Ciani, M., and Comitini, F. (2006). Influence of temperature and oxygen concentration on the fermentation behaviour of Candida stellata in mixed fermentation with Saccharomyces Cerevisiae. World J. Microbiol. Biotechnol. 22, 619-623. doi: 10.1007/s11274-005-9080-6

Contreras, A., Hidalgo, C., Henschke, P. A., Chambers, P. J., Curtin, C., and Varela, C. (2014). Evaluation of non-Saccharomyces yeasts for the reduction of alcohol content in wine. Appl. Environ. Microbiol. 80, 1670-1678. doi: 10.1128/AEM.03780-13

Darling, A. C., Mau, B., Blattner, F. R., and Perna, N. T. (2004). Mauve: multiple alignment of conserved genomic sequence with rearrangements. Genome Res. 14, 1394-1403. doi: 10.1101/gr.2289704

Demuyter, C., Lollier, M., Legras, J.-L., and Le Jeune, C. (2004). Predominance of Saccharomyces uvarum during spontaneous alcoholic fermentation, for three consecutive years, in an Alsatian winery. J. Appl. Microbiol. 97, 1140-1148. doi: 10.1111/j.1365-2672.2004.02394.x

Díaz-Montaño, D. M., Délia, M. L., Estarrón-Espinosa, M., and Strehaiano, P. (2008). Fermentative capability and aroma compound production by yeast strains isolated from Agave tequilana Weber juice. Enzyme Microb. Technol. 42, 608-616. doi: 10.1016/j.enzmictec.2007.12.007

Engel, S. (2013). The Reference Genome Sequence of Saccharomyces cerevisiae: Then and Now. Available online at: (Accessed January 28, 2016).

Erny, C., Raoult, P., Alais, A., Butterlin, G., Delobel, P., Matei-Radoi, F., et al. (2012). Ecological success of a group of Saccharomyces cerevisiae/Saccharomyces kudriavzevii hybrids in the Northern European wine-making environment. Appl. Environ. Microbiol. 78, 3256-3265. doi: 10.1128/AEM.06752-11

Gamero, A., Belloch, C., Ibáñez, C., and Querol, A. (2014). Molecular analysis of the genes involved in aroma synthesis in the species S. cerevisiae, S. kudriavzevii and S. bayanus var. uvarum in winemaking conditions. PLoS ONE 9:e97626. doi: 10.1371/journal.pone.0097626.

Gamero, A., Manzanares, P., Querol, A., and Belloch, C. (2011). Monoterpene alcohols release and bioconversion by saccharomyces species and hybrids. Int. J. Food Microbiol. 145, 92-97. doi: 10.1016/j.ijfoodmicro.2010.11.034

Gamero, A., Tronchoni, J., Querol, A., and Belloch, C. (2013). Production of aroma compounds by cryotolerant Saccharomyces species and hybrids at low and moderate fermentation temperatures. J. Appl. Microbiol. 114, 1405-1414. doi: $10.1111 /$ jam. 12126

García-Ríos, E., Gutiérrez, A., Salvadó, Z., Arroyo-López, F. N., and Guillamon, J. M. (2014). The fitness advantage of commercial wine yeasts in 
relation to the nitrogen concentration, temperature, and ethanol content under microvinification conditions. Appl. Environ. Microbiol. 80, 704-713. doi: 10.1128/AEM.03405-13

Goddard, M. R. (2008). Quantifying the complexities of Saccharomyces cerevisiae's ecosystem engineering via fermentation. Ecology 89, 2077-2082. doi: 10.1890/07-2060.1

González, S. S., Barrio, E., Gafner, J., and Querol, A. (2006). Natural hybrids from Saccharomyces cerevisiae, Saccharomyces bayanus and Saccharomyces kudriavzevii in wine fermentations. FEMS Yeast Res. 6, 1221-1234. doi: 10.1111/j.1567-1364.2006.00126.x

Gonzalez, S. S., Gallo, L., Climent, M. A., Barrio, E., and Querol, A. (2007). Ecological characterization of natural hybrids from Saccharomyces cerevisiae and S. kudriavzevii. Int. J. Food Microbiol. 116, 11-18. doi: 10.1016/j.ijfoodmicro.2006.10.047

Gustafsson, F., Jiranek, V., Neuner, M., Scholl, C., Morgan, S., and Durall, D. (2016). The Interaction of two Saccharomyces cerevisiae strains affects fermentation-derived compounds in wine. Fermentation 2:9. doi: 10.3390/fermentation2020009

Holm Hansen, E., Nissen, P., Sommer, P., Nielsen, J. C., and Arneborg, N. (2001). The effect of oxygen on the survival of non-saccharomyces yeasts during mixed culture fermentations of grape juice with Saccharomyces cerevisiae. J. Appl. Microbiol. 91, 541-547. doi: 10.1046/j.1365-2672.2001.01426.x

Howell, K. S., Cozzolino, D., Bartowsky, E. J., Fleet, G. H., and Henschke, P. A. (2006). Metabolic profiling as a tool for revealing saccharomyces interactions during wine fermentation. FEMS Yeast Res. 6, 91-101. doi: $10.1111 /$ j.1567-1364.2005.00010.x

Izquierdo Cañas, P. M., García-Romero, E., Heras Manso, J. M., and FernándezGonzález, M. (2014). Influence of sequential inoculation of Wickerhamomyces anomalus and Saccharomyces cerevisiae in the quality of red wines. Eur. Food Res. Technol. 239, 279-286. doi: 10.1007/s00217-014-2220-1

King, E. S., Kievit, R. L., Curtin, C., Swiegers, J. H., Pretorius, I. S., Bastian, S. E. P., et al. (2010). The effect of multiple yeasts co-inoculations on sauvignon Blanc wine aroma composition, sensory properties and consumer preference. Food Chem. 122, 618-626. doi: 10.1016/j.foodchem.2010.03.021

Lopandic, K., Gangl, H., Wallner, E., Tscheik, G., Leitner, G., Querol, A., et al. (2007). Genetically different wine yeasts isolated from Austrian vine-growing regions influence wine aroma differently and contain putative hybrids between Saccharomyces cerevisiae and Saccharomyces kudriavzevii. FEMS Yeast Res. 7, 953-965. doi: 10.1111/j.1567-1364.2007.00240.x

Masneuf, I., Hansen, J., Groth, C., Piskur, J., and Dubourdieu, D. (1998). New hybrids between saccharomyces sensu stricto yeast species found among wine and cider production strains. Appl. Envir. Microbiol. 64, 3887-3892.

Medina, K., Boido, E., Fariña, L., Gioia, O., Gomez, M. E., Barquet, M., et al. (2013). Increased flavour diversity of Chardonnay wines by spontaneous fermentation and co-fermentation with Hanseniaspora vineae. Food Chem. 141, 2513-2521. doi: 10.1016/j.foodchem.2013.04.056

Milanovic, V., Ciani, M., Oro, L., and Comitini, F. (2012). Starmerella bombicola influences the metabolism of Saccharomyces cerevisiae at pyruvate decarboxylase and alcohol dehydrogenase level during mixed wine fermentation. Microb. Cell Fact. 11:18. doi: 10.1186/1475-2859-11-18

Naumov, G. I., Naumova, E. S., Antunovics, Z., and Sipiczki, M. (2002). Saccharomyces bayanus var. uvarum in tokaj wine-making of slovakia and hungary. Appl. Microbiol. Biotechnol. 59, 727-730. doi: $10.1007 /$ s00253-002-1077-6

Naumov, G. I., and Nikonenko, T. A. (1987). Genomic divergence in cultivated and wild strains of the yeast, saccharomyces sensu stricto: four twin species. Dokl. Biol. Sci. 294, 330-332.

Naumov, G., Masneuf, I., S., Naumova, E., Aigle, M., and Dubourdieu, D. (2000). Association of Saccharomyces bayanus var. uvarum with some french wines: genetic analysis of yeast populations. Res. Microbiol. 151, 683-691. doi: 10.1016/S0923-2508(00)90131-1

Neeley, E. T., Phister, T. G., and Mills, D. A. (2005). Differential real-time pcr assay for enumeration of lactic acid bacteria in wine differential real-time pcr assay for enumeration of lactic acid bacteria in wine. Appl. Environ. Microbiol. 71, 8954-8957. doi: 10.1128/AEM.71.12.8954-8957.2005

Nissen, P., and Arneborg, N. (2003). Characterization of early deaths of nonsaccharomyces yeasts in mixed cultures with Saccharomyces cerevisiae. Arch. Microbiol. 180, 257-263. doi: 10.1007/s00203-003-0585-9
Nissen, P., Neilsen, D., and Arneborg, N. (2004). The relative glucose uptake abilities of non-saccharomyces yeasts play a role in their coexistence with Saccharomyces cerevisiae in mixed cultures. Appl. Microbiol. Biotechnol. 64, 543-550. doi: 10.1007/s00253-003-1487-0

Nissen, P., Nielsen, D., and Arneborg, N. (2003). Viable Saccharomyces cerevisiae cells at high concentrations cause early growth arrest of non-saccharomyces yeasts in mixed cultures by a cell - cell contact-mediated mechanism. Yeast 20, 331-341. doi: 10.1002/yea.965

Oliveira, B. M., Barrio, E., Querol, A., and Pérez-Torrado, R. (2014). Enhanced enzymatic activity of glycerol-3-phosphate dehydrogenase from the cryophilic Saccharomyces kudriavzevii. PLoS ONE 9:e87290. doi: 10.1371/journal.pone.0087290

Pérez-Nevado, F., Albergaria, H., Hogg, T., and Girio, F. (2006). Cellular death of two non-Saccharomyces wine-related yeasts during mixed fermentations with Saccharomyces cerevisiae. Int. J. Food Microbiol. 108, 336-345. doi: 10.1016/j.ijfoodmicro.2005.12.012

Pérez-Torrado, R., Oliveira, B. M., Zemancíková, J., Sychrová, H., and Querol, A. (2016). Alternative glycerol balance strategies among Saccharomyces species in response to winemaking stress. Front. Microbiol. 7:435. doi: $10.3389 /$ fmicb.2016.00435

Pérez-Través, L., Lopes, C. A., Barrio, E., and Querol, A. (2014). stabilization process in saccharomyces intra and interspecific hybrids in fermentative conditions. Int. Microbiol. 17, 213-224. doi: 10.2436/20.1501.01.224

Peris, D., Lopes, C. A, Belloch, C., Querol, A., and Barrio, E. (2012). Comparative genomics among Saccharomyces cerevisiae $\times$ Saccharomyces kudriavzevii natural hybrid strains isolated from wine and beer reveals different origins. BMC Genomics 13:407. doi: 10.1186/1471-2164-13-407

Piškur, J., Rozpedowska, E., Polakova, S., Merico, A., and Compagno, C. (2006). How did saccharomyces evolve to become a good brewer? Trends Genet. 22, 183-186. doi: 10.1016/j.tig.2006.02.002

Pretorius, I. S. (2000). Tailoring wine yeast for the new millennium: novel approaches to the ancient art of winemaking. Yeast 16, 675-729. doi: 10.1002/1097-0061(20000615)16:8<675::AID-YEA585>3.0.CO;2-B

Querol, A., Barrio, E., Huerta, T., and Ramón, D. (1992). Molecular monitoring of wine fermentations conducted by active dry yeast strains. Appl. Environ. Microbiol. 58, 2948-2953.

Rantsiou, K., Dolci, P., Giacosa, S., Torchio, F., Tofalo, R., Torriani, S., et al. (2012). Candida zemplinina can reduce acetic acid produced by Saccharomyces cerevisiae in sweet wine fermentations. Appl. Environ. Microbiol. 78, 1987-1994. doi: 10.1128/AEM.06768-11

R Core Team (2015). R: A language and environment for statistical computing. Vienna: $\mathrm{R}$ Foundation for Statistical Computing. Available online at: https://www.R-project.org/

Redžepović, S., Orlić, S., Sikora, S., Majdak, a., and Pretorius, I. S. (2002). Identification and characterization of Saccharomyces cerevisiae and Saccharomyces paradoxus strains isolated from Croatian vineyards. Lett. Appl. Microbiol. 35, 305-310. doi: 10.1046/j.1472-765X.2002. 01181.x

Rementeria, A. (2003). Yeast associated with spontaneous fermentations of white wines from the "Txakoli de Bizkaia" region (Basque Country, North Spain). Int. J. Food Microbiol. 86, 201-207. doi: 10.1016/S0168-1605(03)00289-7

Rodrigues, A. J., Raimbourg, T., Gonzalez, R., and Morales, P. (2016). Environmental factors influencing the efficacy of different yeast strains for alcohol level reduction in wine by respiration. LWT-Food Sci. Technol. 65, 1038-1043. doi: 10.1016/j.lwt.2015.09.046

Rodríguez, M. E., Pérez-Través, L., Sangorrín, M. P., Barrio, E., and Lopes, C. A. (2014). Saccharomyces eubayanus and Saccharomyces uvarum associated with the fermentation of araucaria araucana seeds in Patagonia. FEMS Yeast Res. 14, 948-965. doi: 10.1111/1567-1364.12183

Rossignol, T., Dulau, L., Julien, A., and Blondin, B. (2003). Genome-wide monitoring of wine yeast gene expression during alcoholic fermentation. Yeast 20, 1369-1385. doi: 10.1002/yea.1046

Sabate, J., Cano, J., Esteve-Zarzoso, B., and Guillamón, J. M. (2002). Isolation and identification of yeasts associated with vineyard and winery by RFLP analysis of ribosomal genes and mitochondrial DNA. Microbiol. Res. 157, 267-274. doi: 10.1078/0944-5013-00163

Saberi, S., Cliff, M. A., and van Vuuren, H. J. J. (2012). Impact of mixed $S$. cerevisiae strains on the production of volatiles and estimated 
sensory profiles of chardonnay wines. Food Res. Int. 48, 725-735. doi: 10.1016/j.foodres.2012.06.012

Salvadó, Z., Arroyo-López, F. N., Barrio, E., Querol, A., and Guillamón, J. M. (2011a). Quantifying the individual effects of ethanol and temperature on the fitness advantage of Saccharomyces cerevisiae. Food Microbiol. 28, 1155-1161. doi: 10.1016/j.fm.2011.03.008

Salvadó, Z., Arroyo-López, F. N., Guillamón, J. M., Salazar, G., Querol, A, and Barrio, E. (2011b). Temperature adaptation markedly determines evolution within the genus Saccharomyces. Appl. Environ. Microbiol. 77, 2292-2302. doi: 10.1128/AEM.01861-10

Scannell, D. R., Zill, O. A., Rokas, A., Payen, C., Dunham, M. J., Eisen, M. B., et al. (2011). The awesome power of yeast evolutionary genetics: new genome sequences and strain resources for the saccharomyces sensu stricto genus. G3 (Bethesda). 1, 11-25. doi: 10.1534/g3.111.000273

Şener, H., and Yildirim, H. K. (2013). Influence of different maceration time and temperatures on total phenols, colour and sensory properties of cabernet sauvignon wines. Food Sci. Technol. Int. 19, 523-533. doi: $10.1177 / 1082013212462229$

Sipiczki, M., Romano, P., Lipani, G., Miklos, I., and Antunovics, Z. (2001). Analysis of yeasts derived from natural fermentation in a tokaj winery. Antonie van Leeuwenhoek 79, 97-105. doi: 10.1023/A:1010249408975

Stribny, J., Gamero, A., Pérez-Torrado, R., and Querol, A. (2015). Saccharomyces kudriavzevii and Saccharomyces uvarum differ from Saccharomyces cerevisiae during the production of aroma-active higher alcohols and acetate esters using their amino acidic precursors. Int. J. Food Microbiol. 205, 41-46. doi: 10.1016/j.ijfoodmicro.2015.04.003

Thomson, J. M., Gaucher, E. A., Burgan, M. F., De Kee, D. W., Li, T., Aris, J. P., et al. (2005). Resurrecting ancestral alcohol dehydrogenases from yeast. Nat. Genet. 37, 630-635. doi: 10.1038/ng1553

Torija, M. J., Rozès, N., Poblet, M., Guillamón, J. M., and Mas, A. (2001). Yeast population dynamics in spontaneous fermentations: comparison between two different wine-producing areas over a period of three years. Antonie van Leeuwenhoek 79, 345-352. doi: 10.1023/A:10120277 18701

Torriani, S., Zapparoli, G., and Suzzi, G. (1999). Genetic and phenotypic diversity of saccharomyces sensu stricto strains isolated from amarone wine. diversity of saccharomyces strains from amarone wine. Antonie Van Leeuwenhoek 75, 207-215. doi: 10.1023/A:1001773916407
Valero, E., Cambon, B., Schuller, D., Casal, M., and Dequin, S. (2007). Biodiversity of saccharomyces yeast strains from grape berries of wineproducing areas using starter commercial yeasts. FEMS Yeast Res. 7, 317-329. doi: $10.1111 / \mathrm{j} .1567-1364.2006 .00161 . \mathrm{x}$

Vendrame, M., Manzano, M., Comi, G., Bertrand, J., and Iacumin, L. (2014). Use of propidium monoazide for the enumeration of viable Brettanomyces bruxellensis in wine and beer by quantitative PCR. Food Microbiol. 42, 196-204. doi: 10.1016/j.fm.2014.03.010

Wang, C., Mas, A., and Esteve-Zarzoso, B. (2015). Interaction between hanseniaspora uvarum and Saccharomyces cerevisiae during alcoholic fermentation. Int. J. Food Microbiol. 206, 67-74. doi: 10.1016/j.ijfoodmicro.2015.04.022

Wang, C., Mas, A., and Esteve-Zarzoso, B. (2016). The interaction between Saccharomyces cerevisiae and non-saccharomyces yeast during alcoholic fermentation is species and strain specific. Front. Microbiol. 7:502. doi: 10.3389/fmicb.2016.00502

Williams, K. M., Liu, P., and Fay, J. C. (2015). Evolution of ecological dominance of yeast species in high-sugar environments. Evolution 69, 2079-2093. doi: $10.1111 /$ evo.12707

Zara, G., Mannazzu, I., Del Caro, A., Budroni, M., Pinna, M. B., Murru, M., et al. (2014). Wine quality improvement through the combined utilisation of yeast hulls and candida zemplinina/Saccharomyces cerevisiae mixed starter cultures. Aust. J. Grape Wine Res. 20, 199-207. doi: 10.1111/ajgw.12078

Zwietering, M. H., Jongenburger, I., Rombouts, F. M., and van't Riet, K. (1990). Modeling of the bacterial growth curve. Appl. Environ. Microbiol. 56, $1875-1881$

Conflict of Interest Statement: The authors declare that the research was conducted in the absence of any commercial or financial relationships that could be construed as a potential conflict of interest.

Copyright (๑) 2017 Alonso-del-Real, Lairón-Peris, Barrio and Querol. This is an open-access article distributed under the terms of the Creative Commons Attribution License (CC BY). The use, distribution or reproduction in other forums is permitted, provided the original author(s) or licensor are credited and that the original publication in this journal is cited, in accordance with accepted academic practice. No use, distribution or reproduction is permitted which does not comply with these terms. 